\title{
Multilocular Cystic Nephroma. Kidney Disease Difficult To Diagnose Before Surgery: A Case Report
}

\author{
Salah Berkane, Mustapha Kheder, Salim Belhkherchi, Chemssedine Benklhelat, Lyazid Mohamedi, Youcef Mahmoudi \\ Department of Medicine, University of Béjaïa, Béjaïa, Algeria
}

^Correspondence to: Salah Berkane; Department of Medicine, University of Béjaïa, Béjaïa, Algeria; E-mail: salahberkane07@yahoo.fr

Received: June 13 ${ }^{\text {th }}, 2020$; Accepted: June 23 ${ }^{\text {rd }}, 2020$; Published: July $7^{\text {th }}, 2020$

Citation: Berkane S, Kheder M, Belhkherchi S, Benklhelat C, Mohamedi L, Mahmoudi Y. Multilocular cystic nephroma. Kidney disease difficult to diagnose before surgery: A case report. Gen Surg Open A Open J. 2020; I(1): 24-27.

\begin{abstract}
Cystic nephroma is a benign renal lesion. It is a benign and rare cystic tumor of the kidney whose diagnosis needs renal specimen after nephrectomy. We report an observation of 62-year-old woman, obese with a history of type 2 diabetes who consults for left lumbar pain without hematuria. The examination found no lumbar contact or signs of urinary tract infection. The first exploration by an abdominal echotomographic shows the existence of an inferior medieval and polar lesion of $84 \mathrm{~mm}$ of the large axis, heterogeneous with multiple anechoic zones within it of small sizes. The interpretation made by the radiologist retained 3 possible diagnoses, namely: a renal mass suspected of malignancy, a heterogeneous multicystic lesion and a hydatid cyst stage III of Gerbi. The computed tomography found a heterodyne left medieval tumor process and lower polar poorly limited with several areas of necrosis of $80 \mathrm{~mm}$ of large diameter taking the contrast and interpreted as a malignant lesion, without hilar lymphadenopathies or retroperitoneal visible. The rest of the extension balance sheet was free of anomalies. Hydatid serology was performed and returned negative. The patient was operated on with the diagnosis of kidney cancer. The intraoperative exploration showed the existence of a left kidney increased in volume in its compartment, the accidental break-in of the latter allowed even the multilocular cystic appearance of small infracentimetric sizes of this lesion. An enlarged total nephrectomy was realized. Macroscopic examination of the part reveals a kidney carrying multiple cystic lesions arranged one against the other without nephrogenic tissue in the septic letting out a clear liquid. The pathology study showed the appearance of a multilocular cystic nephroma. Our patient is alive at $48 \mathrm{months}$ and in well health.
\end{abstract}

Keywords: Multilocular cystic nephroma; kidney cystadenoma.

\section{INTRODUCTION}

Cystic nephroma has been described in the past with a variety of names such as renal multilocular cyst, renal cystadenoma, adult benign nephroblastoma, and by the polycystic kidney. ${ }^{1}$ It is a benign and rare cystic tumor of the kidney. The semiological and clinical data are not specific for this pathology. The problem of this affection remains its diagnosis which is very difficult before the histological study because recognized surgery is conservative (partial nephrectomy) when the site and the size of the lesion allow it. Unfortunately, only the anatomopathological study makes it possible to confirm the diagnosis and to eliminate a multilocular cystic renal carcinoma or a necrotic pseudocysts carcinoma. We report an observation of a cystic nephroma originally diagnosed as kidney cancer. Through the synthesis of the literature, we emphasize recent physiopathological and immunohistochemical knowledge likely to improve the management of this benign disease for which a neoplastic evolution remains possible.

\section{OBSERVATION}

It is patient $\mathrm{BD}, 62$-years-old, woman, obese with a history of type 2 diabetes who consults for left lumbar pain without hematuria. The examination found no lumbar contact or signs of urinary tract infection. The first exploration by an abdominal echotomography shows the existence of an inferior medieval and polar lesion of $84 \mathrm{~mm}$ of the large axis, heterogeneous with multiple anechoic zones within it of small sizes. The interpretation made by the radiologist retained 3 possible diagnoses, namely: A renal mass suspected of malignancy, a heterogeneous multicystic lesion and a hydatid cyst stage III of Gherbi. The computed tomography found a heterodyne left medieval tumor process and lower polar poorly limited with several areas of necrosis of $80 \mathrm{~mm}$ of large diameter taking the contrast and interpreted as a malignant lesion, without hilar lymphadenopathies or retroperitoneal visible. The rest of the extension balance sheet was free of anomalies. Hydatid serology was performed and returned negative. The patient was operated on with the diagnosis of kidney cancer. The intervention was led by a median transperitoneal laparotomy. The intraoperative exploration showed the existence of a left kidney increased in volume in its compartment, the accidental break-in of the latter allowed even the multilocular cystic appearance of small infracentimetric sizes of this lesion. An enlarged total nephrectomy was realized. Macroscopic examination of the part reveals 
a kidney carrying multiple cystic lesions arranged one against the other without nephrogenic tissue in the septic letting out a clear liquid. The pathology study showed the appearance of a multilocular cystic nephroma. Our patient is alive at 48-months and she is in good health[Figure 1-2].

Figure 1. Heterogeneous inferior mediorenal and polar lesion containing multiple anechogenic zones.

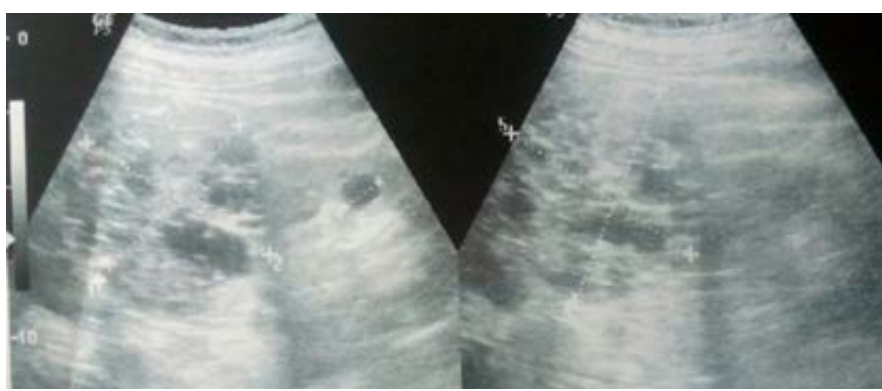

Figure 2. Computed tomography image of a multilocular cystic nephroma.
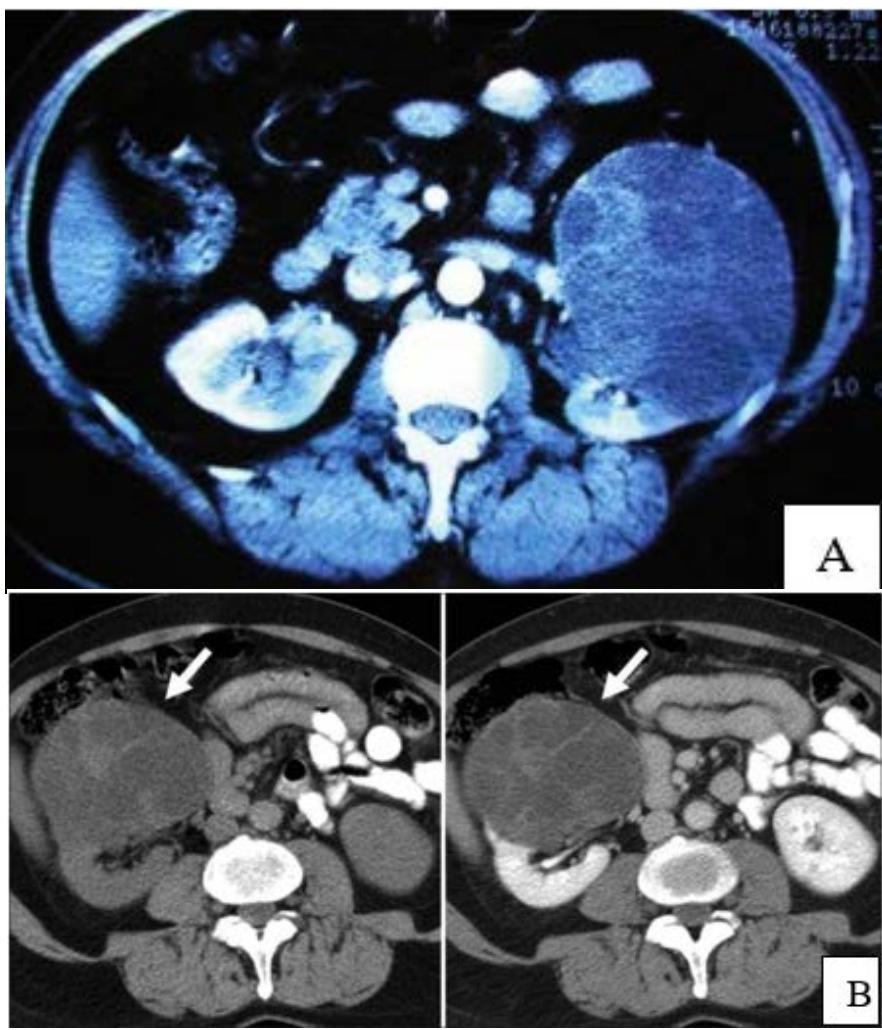

\section{DISCUSSION}

Cystic nephroma is a rare histological entity with less than 250 cases described in the literature. It is a benign and not hereditary pathology. ${ }^{1}$ This lesion was first described in the literature by Edmunds in 1892 under the name of "kidney cystadenoma". Most cases are asymptomatic and accidentally discovered during exploration for urinary signs not specific to the morphology. ${ }^{2}$ It can be an abdominal mass, especially in children. There seems to be a bimodal distribution in the population: on the one hand in children under 10 -years-old, mainly young boys under 4 -yearsold and on the other hand in adults 50-60 years old, mainly women with a sex ratio of 3.5. ${ }^{3}$ Ninety percent of nephroblastomas-cystic nephrons occur in children. ${ }^{4}$ Our patient is a woman and 62-years-old, almost in the same age group found in the literature. The tumor was unilateral and located on the left side[Figure 3].

Figure 3. View of the open tumor. Appearance of a multilocular cystic lesion.
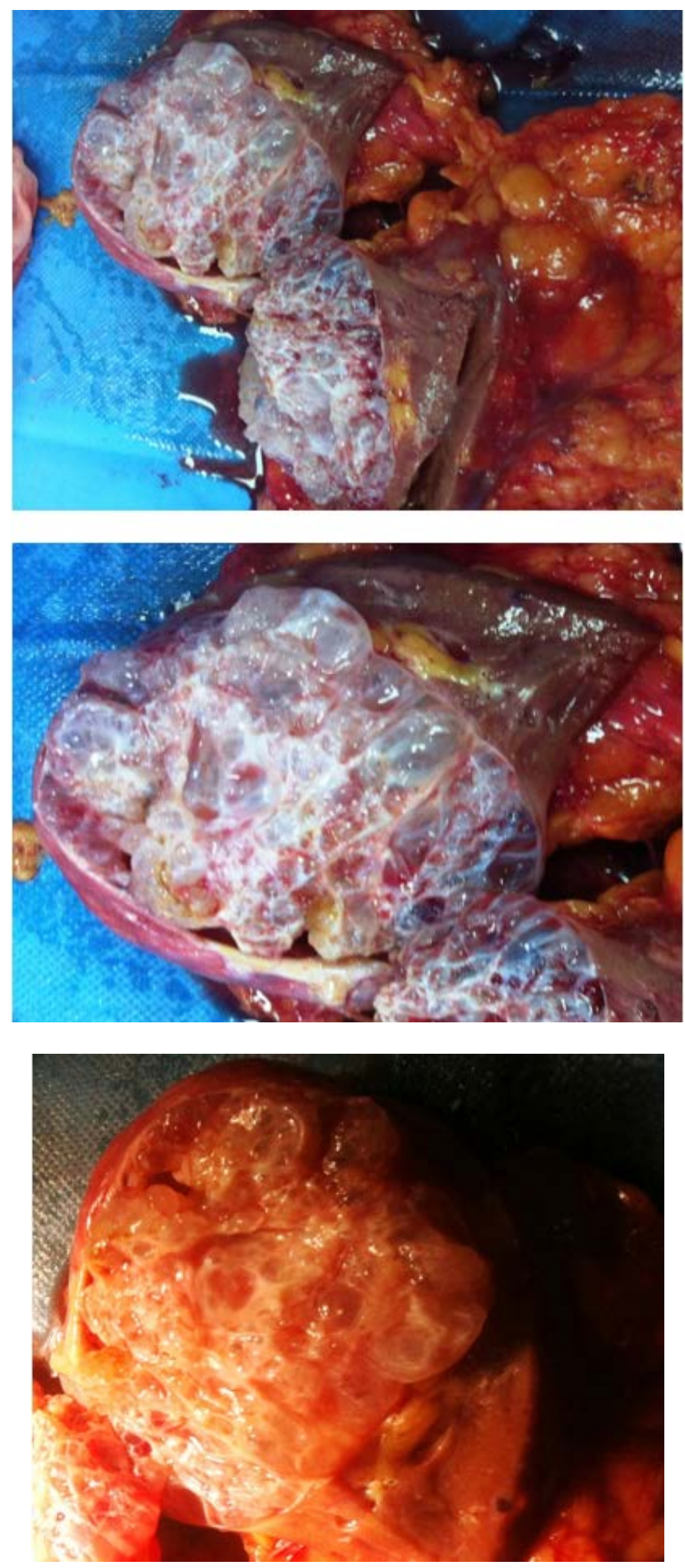

The etiopathogenesis of multicystic nephroma is not yet 
known and there are several theories about its etiopathogenesis. Developmental failure and neoplastic origin have been reported as an etiology of multicystic nephroma. Congenital cystic nephroma is mainly linked to Wilms' tumor as a benign cystic defect but some cases of degeneration have been reported. The diagnostic criteria were established by Powel et al. ${ }^{5}$ In 1951, the latter described the lesion as a malformation of the development of the kidney. Steel et al. ${ }^{6}$ mentioned the possibility of Mullerian stromal cells in the kidney since the tumor is similar to the ovarian stroma. Sanjay et al. ${ }^{7}$ reported tissues of the corpus Albicans and corpus fibrosum type in cystic nephroma and an ovarian type immuno-stroma stained positively for progesterone and estrogen. This author and al reported that multicystic nephrotic cells were positive for several markers of the distal tube and the collecting duct (CK19, CK AE1 / AE3, EMA) and the proximal tube (alfa-1 antitrypsin, Lisosim, CD15, CD10). These immunohistochemical results suggest tubular differentiation in cells. Some of the male patients diagnosed with multicystic nephroma were on hormone therapy for prostate cancer[Figure 4].

Figure 4. Detail of the wall of a multilocular cystic nephroma: appearance of an upholsterer nail. Optical microscopy (HES, GO x 250).

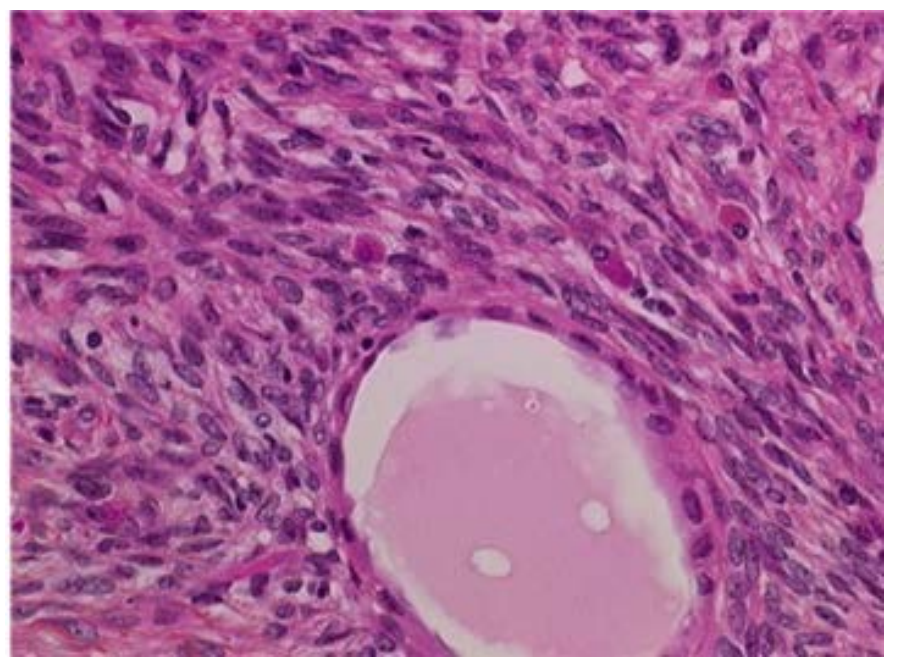

In a recent study, ${ }^{8}$ it was reported that eyelashes and microvilli-like structures, such as nephron collecting tubes, were identified by electron microscopy in a case of cystic nephroma.

Currently, the diagnosis is based on the 8 anatomic-radiological criteria proposed by Powell and Boggs, ${ }^{9}$ which are:

1) unilaterality, 2) solitary character, 3) multilocular lesion, 4) cysts not communicating with each other, 5) cysts not communicating with the pelvis, 6) cysts coated with a flattened epithelium, 7) absence of nephrogenic tissue at the level of septic and 8) normal appearance of residual renal tissue. All these criteria were found in our case. In 1989, Joshi and Beckwith ${ }^{10}$ modified these criteria which became by decreasing them to 5 (A to E) [Table 1].

A] the tumor is entirely composed of cysts and their septa; B] cystic nephroma is a discrete well-defined mass; C] the septa are the only solid component and conform to the contours of the cyst without expansive nodules; D] the cysts are covered with a flattened, cubic or shelled epithelium; And e] the septic contain fibrous tissue, in which well-differentiated tubules may be present [Table 2].
Table 1. Powel and Boggs anatomo-pathological criteria

\begin{tabular}{|l|l|}
\hline 1 & Lonely character, \\
\hline 2 & Unilaterality, \\
\hline 3 & Multilocular lesion, \\
\hline 4 & Cysts not communicating with each other, \\
\hline 5 & Cysts not communicating with the pelvis, \\
\hline 6 & Cysts coated with a flattened epithelium, \\
\hline 7 & Absence of nephrogenic tissue in the septa \\
\hline 8 & Normal appearance of residual renal tissue. \\
\hline
\end{tabular}

Table 2. The Joshi and Beckwith criteria

\begin{tabular}{|c|l|}
\hline A & The tumor is entirely composed of cysts and their septa; \\
\hline B & Cystic nephroma is a discrete well-defined mass; \\
\hline C & $\begin{array}{l}\text { The septa are the only solid component and conform to the contours of the } \\
\text { cyst without expansive nodules; }\end{array}$ \\
\hline D & The cysts are covered with a flattened, cubic or shell epithelium; \\
\hline E & $\begin{array}{l}\text { The septa contain fibrous tissue, in which well-differentiated tubules may } \\
\text { be present. }\end{array}$ \\
\hline
\end{tabular}

The performance of current imaging, and more particularly that of helical acquisition CT scans, in most cases, allows the benign aspect of this type of lesion to be characterized. It clearly shows the presence of a well-defined mass, appearing avascular or hypovascularized, of multicystic appearance and presenting fine septas discreetly taking contrast (average density from 2 to 40 Hounsfield Units). It also highlights possible calcifications in the thickness of the septic. However, LEVY ${ }^{11}$ rightly recalls that all of these CT criteria are not specific enough to formally exclude the possibility of a malignant lesion of a necrotic nature. In our patient, the radiologist interpreted the image computed tomography as a heterogeneous process with multiple areas of non-cystic necrosis in favor of kidney cancer. Nuclear magnetic resonance and arteriography, unfortunately, do not seem to be able to provide additional decisive arguments. Likewise, few authors report a diagnosis of certainty on a fine needle biopsy puncture, due to the lack of communication between the cysts and the scarcity of the material collected.

Multilocular cystic nephroma presents as cystic lesions without communications or relationships with the pelvis. These cystic lesions have a cubic or endothelium epithelial coating. It is classic to note the absence of nephrogenic tissue in the septa with an exclusively healthy renal parenchyma on the rest of the operating room (except in children where we then speak of cystic nephroblastoma).

Surgery is recommended for the treatment of patients diagnosed with multicystic nephroma including excision of the lesion. ${ }^{12}$ The 2 techniques used are partial nephrectomy and radical nephrectomy. Radical nephrectomy remains the most common approach because it is difficult to accurately diagnose and determine the risk of malignancy of the lesion. Only a careful extemporaneous examination of intraoperative samples can allow this uncertainty to be avoided and thus avoid an unnecessary nephrectomy. Conservative surgery seems to be the most appropriate therapeutic attitude in adults with a well-defined lesion, the nature of which would be confirmed by extemporaneous histological examination. ${ }^{13}$ We suggest that partial nephrectomy is an optimal treatment if the diagnosis of cystic nephroma is strongly suspected preoperatively and it will be checked during intraoperative. Cystic nephroma is considered to be mild in adults but tumor recurrences have been observed. These recurrences are more frequent after partial nephrectomy. 
So far, only four cases of local recurrence have been reported, all after partial nephrectomy. However, in a series of 24 patients who underwent a partial nephrectomy for cystic nephroma, no recurrence was found after an average follow-up of 39-months. ${ }^{14} \mathrm{C}$-P. Chang et al, ${ }^{15}$ reported a similar case to that of our patient with the same radical surgery. More recently, a case of percutaneous treatment has been described in the treatment of cystic nephroma. Percutaneous endoscopic resection of part of the cyst protruding into the renal parenchyma was performed, and CT follow-up 4 weeks later revealed complete resolution. However, 3-years later, the authors report a failure with a percutaneous approach.

\section{CONCLUSION}

Multicystic nephroma is a rare benign tumor with a good prognosis. The differential clinical and radiological diagnosis with renal cystic carcinomas remains difficult. Thus, histopathological examination of surgical samples is very essential in the process of differential diagnosis. Positive estrogen receptor damage with histopathological similarity to the ovarian stroma supports the hormonal theory. Therefore, surgery is recommended for diagnosis and treatment.

\section{REFERENCES}

1. Sambus C, Albouy B, Riopel C, Gobet F, Grise P, Pfister C. Adult multilocular cystic nephroma: Diagnostic and therapeutic strategy. Progress in Urology. 2005; 15, 315-318.

2. Thibeau JF, Sourtzis S, Lufuma M, Devuyst E, Vandendris M. Adult multilocular cystic nephroma. Unusual presentation and literature review. Prog Urol. 2001; 11: 507-511.

3. Dell'Atti L. Department of Urology, University Hospital St. Anna, Ferrara, Italy An unusual presentation of cystic nephroma in an adult man rare tumors. 2015; 7: 5860 .

4. Wani DB, Kolte G, Rathod V, Banode P, Bhol A. Asymptomatic Infantile Cystic Nephroma: A diagnostic. Indian J Surg. 2012.

5. Powell T, Shakman R, Johnson HD. Multilocular cysts of the kidney.

\section{Br J Urol.1951;142-152}

6. Steele R, Daroca PJ, Hill S, Reed RJ, Thomas R. Multilocular renal cyst (cystic nephroma) with müllerian-like stroma. Urology. 1994; 43 : 549-553.

7. Sanjay M, Valente AL, de la Roza G. Cystic nephroma A histologic and immunohistochemical study of 10 cases. Arch Pathol Lab Med. $2004 ; 128$.

8. Tajima S, Waki M. Cystic partially differentiated nephroblastoma in an adult : A case imitating the process of normal nephrogenesis along with corresponding WT1. Int J Clin Exp Pathol. 2015.

9. Boggs LK, Kimmestiel P. Begnin multilocular cystic nephroma: Report of two cases of so-called multilocular cyst of the kidney. J Urol. 1956; $76: 530-541$.

10. Joshi VV, Beckwith JB. Multilocular cyst of the kidney (cystic nephroma) and cystic, partially differentiated nephroblastoma. Terminology and criteria for diagnosis. Cancer. 1989; 64 (2): 466-479.

11. Levy P, Helenon O, Merran S, Paraf F, Mejean A, Cornud F, Moreau JF. Cystic tumors of the kidney of adults: Radio-histopathological correlations. J Radiol. 1999; 80: 121-133.

12. Statoua M, Yddousalah O, Ziouziou I, et al. Adult multilocular cystic nephroma: A case report and review of the literature. African Journal of Urology.

13. Dong B, Wang Y, Zhang J, Fu Y, Wang G. Multilocular cystic nephroma treated with laparoscopic nephron-sparing surgery. CUAJ. 2014; 8: 7-8.

14. Castillo OA, Boyle ET, Jr Kramer SA. Multilocular cysts of kidney. A study of 29 patients and review of literature. Urology. 1991; 37: 156-62.

15. Chang CP, Li JR, Yang CS, Ou YC, Cheng CL. Multilocular cystic nephroma: A case report and review of the literature. Urological Science. 2014; $109 \mathrm{e} 111$. 